\title{
Multiobjective Optimization in Micromachining of Aluminum (Al 7075) using Taguchi Technique
}

\author{
V.S.Kathavate and A.S.Adkine
}

\begin{abstract}
In present scenario, the demand for precise micro components in the field of aerospace, mechanical, optics, electronics and biotechnology is increasing. This current work aims for optimization in micromilling of Al 7075 material using Taguchi robust technique. This work is carried out under three stages; experimental work, modelling and multiobjective optimization. Initially, micromilling experiments are carried out by constructing taguchi L9 orthogonal array keeping spindle speed, feed rate and depth of cut as controlled process variables, while results are analyzed using MINITAB 15 software for the responses Metal removing rate and Surface roughness. Regression Model replicating MRR and Surface roughness is created. To optimize all responses, Taguchi signal to noise ratio is used. Finally, analysis of variance (ANOVA) is done and multiobjective optimization results are predicted. It was found that for the optimized conditions of MRR and surface roughness spindle speed should be kept $2600 \mathrm{rpm}$, feed rate $600 \mathrm{~mm} / \mathrm{min}$ and depth of cut should be in the range of $0.07 \mathrm{~mm}$. From ANOVA it can be anticipated that feed rate is the most influencing factor which contributes $65 \%$ followed by spindle speed $18 \%$ and depth of cut $10 \%$. It can be said that metal removing rate is adversely affected by feed rate while surface roughness is influenced by spindle speed.
\end{abstract}

Key Words - Depth of Cut (DoC), feed rate, Metal removing rate (MRR), Micromachining, Multiobjective optimization, Signal to Noise $(\mathrm{S} / \mathrm{N})$, Spindle speed, Surface roughness, Taguchi method.

\section{INTRODUCTION}

Increase in demand for the micro products with precise machining and superior surface finishing is gaining more significance and has versatile impact on national security, defence, energy, healthcare and domestic manufacturing base [1]. Non-traditional fabrication methods such as laser machining, focused ion beam machining, electrochemical machining and electro discharge machining (EDM) are used to produce micro components, but these methods have limited potential due to the limited work piece material selection, poor productivity and high cost[2]. But micromachining process such as micro-milling, microdrilling and micro-grinding are gaining more importance over nontraditional machining process [3]. So, it is capable

Manuscript published September 30, 2016. This work was carried out in the tool room Pravin Engineering Pvt. Ltd. Waluj, Aurangabad and Micronics Calibration Centre, Chikalthana, Aurangabad.

V.S.Kathavate, Project Scientist-I (Mechanical), National Institute of Ocean Technology, Pallikaranai, Chennai 600100, (Tamilnadu) India. (e-mail: kathavate_vaibhav@rediffmail.com).

A.S.Adkine, Assistant Professor, Shreeyash College of Engineering and Technology, Aurangabad, 431009, (Maharashtra) India.

(e-mail: amoladkine@gmail.com). of producing 2- dimensional surfaces with third dimension $\left(2 \frac{1}{2} \mathrm{D}\right)$.

Micromachining of any metal often consists of using miniature cutting tool which may derived from macro tool[4]. Tools used for turning, milling and drilling in micromachining are very small in diameter upto $10 \mu \mathrm{m}$. Complex structures with high aspect ratios and tedious geometries can be suitably produced by micromilling process. Surface roughness may be increased due to elastic recovery and minimum chi thickness provided that chip thickness should be less than cutting edge radius of micro tool. Ali and Ong used focussed ion beam sputtering for the fabrication of microtools[5]. Polycrystalline diamond micro hexagonal tool was fabricated by Cheng et. al. using wire electrical discharge machining process[6]. Suzuki et.al. had developed the micro tool made of polycrystal diamond[7].

Micro machinability of copper 101 was reported by Sinan Filiz et.al.[4]. Whereas, G. Bissacco et.al. investigated the micro milling of hardened tool steel[8]. From the variety of materials such as polymer [9], steel, aluminum, tungsten carbide [10], brass [11] and silicon [12] manufacturing of complex shapes such as two dimensional and three dimensional structures are possible using micromilling. Though there is moderate research on micro milling of steel, copper and composites, very few carried the experimentation on aluminum.

There are various process parameters which have direct influence on micro milling performance. Cutting forces, tool inclination angle, spindle speed, feed rate and depth of cut are few of them. Most of the researchers have optimized process parameters and their influence by various methods like response surface methodology (RSM), central composite design (CCD), full factorial and fractional factorial. Few of them were decided to go with Taguchi method.

Taguchi technique is one of the most suitable and advanced technique for optimizing process parameters in machining process in current scenario. It consists of specially constructed orthogonal arrays $\left(\mathrm{L}_{8}, \mathrm{~L}_{9}, \mathrm{~L}_{18}\right.$ and $\left.\mathrm{L}_{27}\right)$ and gives much reduced variance. It gives the idea about what optimal settings of process parameters affect the responses in the particular process. Using Taguchi method, one can reduce its number of experimentations by huge margin, like if anyone has 13 process parameters and there 3 respective levels then instead of going for $\left(3^{13}\right)$ experiments, able to get the similar results in 27 experiments ( $\mathrm{L}_{27}$ array). So, here in this work, the effects of process 
parameters spindle speed, feed rate and depth of cut were studied using taguchi robust technique and design was optimized for surface responses like metal removing rate (MRR) and surface roughness using multiobjective optimization. Signal to Noise ratios were calculated for best suitable design. Regression model was created for predicting the accuracy and confirmation of results.

\section{EXPERIMENTAL}

\section{A. Material}

The micromilling tests were conducted on Aluminum material of grade (Al 7075) and having dimensions $60 \mathrm{~mm} \times 35 \mathrm{~mm} \times 20 \mathrm{~mm}$. Initially the desired dimension parts of $\mathrm{Al}$ (7075) were machined by surface grinding. Surface roughness was maintained upto $1 \mu \mathrm{m}$. Vickers hardness of the material was determined using diamond indenter and found to be around 130. The chemical composition of Aluminum (Al 7075) was determined by energy dispersive spectroscopy (EDAX) (Table 1);

TABLE 1: Chemical Composition of Al 7075

\begin{tabular}{cc}
\hline Element & wt \% \\
\hline Aluminum $(\mathrm{Al})$ & 88.3 \\
Zinc $(\mathrm{Zn})$ & 4.8 \\
Silicon $(\mathrm{Si})$ & 0.84 \\
Manganese $(\mathrm{Mn})$ & 0.34 \\
Lithium $(\mathrm{Li})$ & 0.0002 \\
\hline
\end{tabular}

Tool for machining purpose was selected in accordance with material specifications and according to machine performance. A flat end milling cutter of $2 \mathrm{~mm}$ diameter was selected for carrying out the experiment which was having a $40 \mathrm{~mm}$ end mill length and $5 \mathrm{~mm}$ shank diameter. The static run out of the tool from the spindle axis was $7 \mu \mathrm{m}$. All the micro milling experiments were carried out on the machine of Heartford (E-2 series) VMC milling machine (figure 1). While machining was done on the area $30 \mathrm{~mm} \times 15 \mathrm{~mm}$ surface with $1.5 \mathrm{~mm}$ depth.

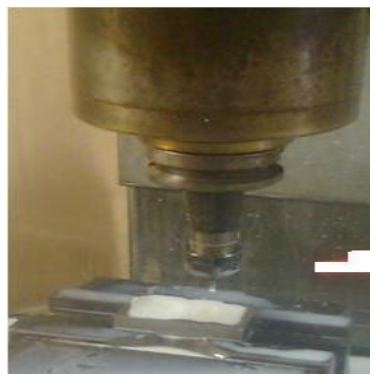

Fig. 1. Micro milling of Al 7075

\section{B. Selection of Process Variables}

Input controlled variables Spindle speed (rpm), feed rate $(\mathrm{mm} / \mathrm{min})$ and Depth of cut $(\mathrm{mm})$ were designed according to the trial and error basis method that the material can withstand with and according machine specifications so as to achieve optimum values of Metal removing rate and Surface Roughness (Table 2);
TABLE 2: Process Parameters and their levels

\begin{tabular}{ccccc}
\hline Code & Process parameters & Level 1 & Level 2 & Level 3 \\
\hline A & Spindle Speed $(\mathrm{rpm})$ & 2200 & 2600 & 3000 \\
B & Feed Rate $(\mathrm{mm} / \mathrm{min})$ & 400 & 500 & 600 \\
C & Depth of Cut (mm) & 0.05 & 0.07 & 0.09 \\
\hline
\end{tabular}

\section{Construction of Taguchi L ${ }_{9}$ Orthogonal Array}

Taguchi method consists of specially constructed Taguchi orthogonal arrays. These orthogonal arrays are the outcome (matrix) of the equation (Levels Process Variables). Now, here we have 3 process variables with their 3 levels. So, Taguchi L9 orthogonal array was created and experiments were run according array (Table 3). For the sake of repeatability and precision measurements, each experiment was conducted twice.

TABLE 3: Taguchi L ${ }_{9}$ Orthogonal Array

\begin{tabular}{cccc}
\hline Experiment & Spindle & Feed & Depth of \\
\hline 1 & 1 & 1 & 1 \\
3 & 1 & 2 & 2 \\
4 & 1 & 3 & 3 \\
5 & 2 & 1 & 2 \\
6 & 2 & 2 & 3 \\
7 & 2 & 3 & 1 \\
8 & 3 & 1 & 3 \\
9 & 3 & 2 & 2 \\
\hline
\end{tabular}

\section{RESULTS AND DISCUSSION}

There are various factors which influences during micro milling operations such as tool wear, cutting forces and microstructure of the work piece. The main purpose of this work was to optimize the surface responses like metal removing rate and surface roughness.

\section{A. Measurements}

Measurements for the metal removing rate in $\mathrm{gm} / \mathrm{min}$ was carried out using the governing equation, the difference between mass of the workpiece after machining and mass of the workpiece before machining per unit machining time. Here in micromilling experiments the machining time was kept constant upto 18 mins (Table 4);

$$
M R R=\frac{m a-m b}{T} \quad(\mathrm{gm} / \mathrm{min})
$$

Where, $\mathrm{m}_{\mathrm{a}}=$ Mass of the workpiece after machining $\mathrm{m}_{\mathrm{b}}=$ Mass of the workpiece before machining $\mathrm{T}=$ Machining time (18 mins) 
TABLE 4: Mass difference between workpiece

\begin{tabular}{ccc}
\hline Sr.No. & $\begin{array}{c}\text { Mass before } \\
\text { machining }(\mathbf{g m})\end{array}$ & $\begin{array}{c}\text { Mass after } \\
\text { machining }(\mathbf{g m})\end{array}$ \\
\hline 1 & 140.50 & 122.63 \\
2 & 142.52 & 126.76 \\
3 & 140.38 & 125.63 \\
4 & 140.76 & 127.48 \\
5 & 142.90 & 129.80 \\
6 & 143.62 & 127.10 \\
7 & 141.45 & 124.22 \\
8 & 140.50 & 123.28 \\
9 & 140.50 & 122.30 \\
\hline
\end{tabular}

Surface roughness is one of the influencing parameter in production process which determines the quality of finished products. Surface roughness was measured in the direction of feed by the Taylor Hobson Make Surface Finish Tester, Seltronic 3 with offline and real time monitoring condition. The profilometer was calibrated with a standard calibration block. Average surface roughness $(\mathrm{Ra})$ was selected as a roughness parameter. The measurement of $\mathrm{Ra}$ was repeated ten times and average values of these measurements were taken into consideration to make further analysis (Table 5);

TABLE 5: Surface roughness's of the machined workpiece

\begin{tabular}{cc}
\hline Sr.No. & Surface roughness $(\boldsymbol{\mu m})$ \\
\hline 1 & 0.40 \\
2 & 0.37 \\
3 & 0.48 \\
4 & 0.52 \\
5 & 0.28 \\
6 & 1.10 \\
7 & 0.65 \\
8 & 0.38 \\
9 & 0.46 \\
\hline
\end{tabular}

TABLE 6: Final result matrix

\begin{tabular}{cccccc}
\hline Sr.No. & $\begin{array}{c}\text { Spindle } \\
\text { speed }\end{array}$ & $\begin{array}{c}\text { Feed } \\
\text { rate }\end{array}$ & $\begin{array}{c}\text { Depth } \\
\text { of cut }\end{array}$ & MRR & $\begin{array}{c}\text { Surface } \\
\text { Roughness } \\
(\boldsymbol{\mu m})\end{array}$ \\
\hline 1 & 2200 & 400 & 0.05 & 0.992 & 0.27 \\
2 & 2200 & 500 & 0.07 & 0.875 & 0.37 \\
3 & 2200 & 600 & 0.09 & 0.819 & 0.48 \\
4 & 2600 & 400 & 0.07 & 0.737 & 0.52 \\
$\mathbf{6}$ & 2600 & 500 & 0.09 & 0.561 & 0.28 \\
$\mathbf{7}$ & 2600 & 600 & 0.05 & 0.584 & 1.10 \\
$\mathbf{8}$ & 3000 & 400 & 0.09 & 0.957 & 0.30 \\
$\mathbf{9}$ & 3000 & 500 & 0.05 & 0.956 & 0.38 \\
\hline
\end{tabular}


TABLE 8: Analysis of Variance for metal removing rate

\begin{tabular}{cccccc}
\hline Source & DF & SS & MS & F & P \\
\hline Spindle Speed & 2 & 0.18902 & 0.945 & 0.25 & 0.859 \\
Feed Rate & 2 & 0.65672 & 0.3234 & & \\
Depth of Cut & 2 & 0.07577 & 0.038 & & \\
Residual error & 2 & 0.07849 & 0.03925 & & \\
Total & 8 & 1 & & & \\
\hline
\end{tabular}

Influence of depth of cut on MRR is more about $65.67 \%$, spindle speed contributes $18.90 \%$ followed by depth of cut $7.5 \%$. Interval plot of MRR influenced by factor spindle speed suggests the optimal speed of $2600 \mathrm{rpm}$ to $3000 \mathrm{rpm}$ is suitable for achieving maximum metal removing rate (figure 3). Experimental validation with model was in agreement with each other being shown in (figure 4).

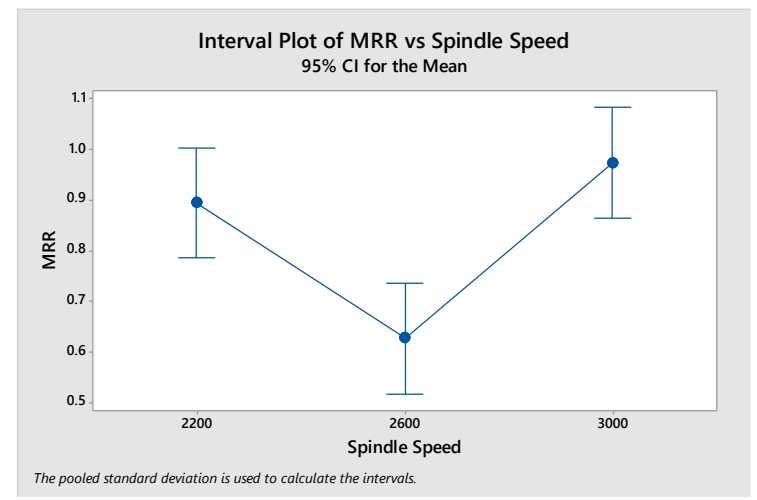

Fig. 3. Interval plot for MRR vs Spindle speed

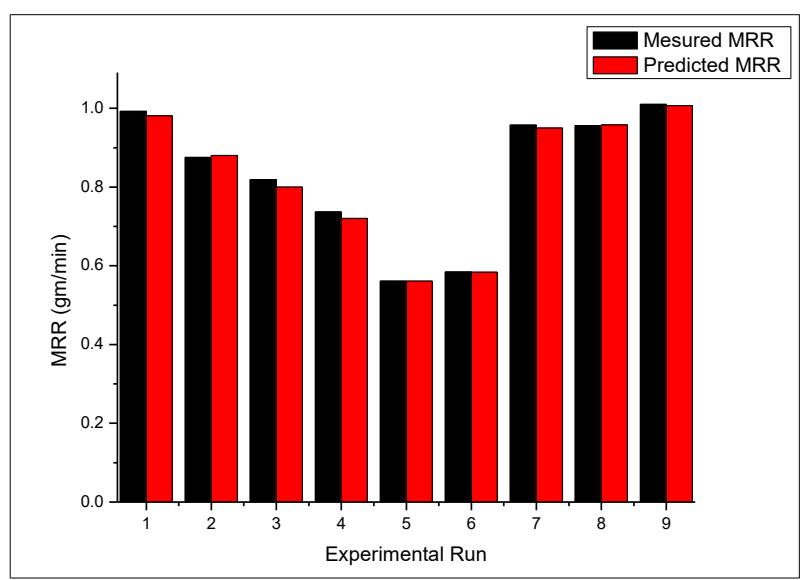

Fig. 4. Comparative study for metal removing rate

\section{Regression analysis for Surface roughness}

Being as one of the response factor, regression analysis was done for surface roughness using MINITAB 15 software. The model generated for surface roughness is given by,

$\mathrm{SF}=0.45+0.00011 \mathrm{~A}-0.000783 \mathrm{~B}-0.145 \mathrm{C}$

TABLE 9: Regression analysis for surface roughness

\begin{tabular}{ccccc}
\hline Predictor & Coefficient & SE Coef. & T & P \\
& & & & \\
\hline Constant & 0.4520 & 0.645 & 1.68 & 0.230 \\
Spindle Speed & 0.0001099 & 0.0010989 & 0.78 & 0.59 \\
Feed Rate & -0.00078299 & 0.0007829 & -0.58 & 0.690 \\
Depth of Cut & -0.14502 & 2.59 & -0.85 & 0.64 \\
\hline
\end{tabular}

Weighted analysis using weights in Surface roughness,

$\mathrm{S}=0.28546 \quad \mathrm{R}-\mathrm{Sq}=95.4 \% \quad \mathrm{R}-\mathrm{Sq}(\operatorname{adj})=87.8 \%$

PRESS $=0.689$ R-Sq (pred) $=0.00 \%$

The parameter R-sq gives the idea about the amount of variation observed in surface roughness and is explained by the input factors. $\mathrm{R}-\mathrm{sq}=95.4 \%$ generalises that the model is able to predict the response with high accuracy (Table 8). Adjusted R-sq is modified R-sq that has been adjusted for the no. of terms in the model. If unnecessary terms are included in the model, R-sq can be artificially high, but adjusted R-sq $(87.8 \%)$ may get smaller. The standard deviation of error in the modelling, $\mathrm{S}=0.28546$. Predicted model and actual surface roughness are the fitted to regression line. It was found that all the observations agreements with governing single trend line (figure 5).

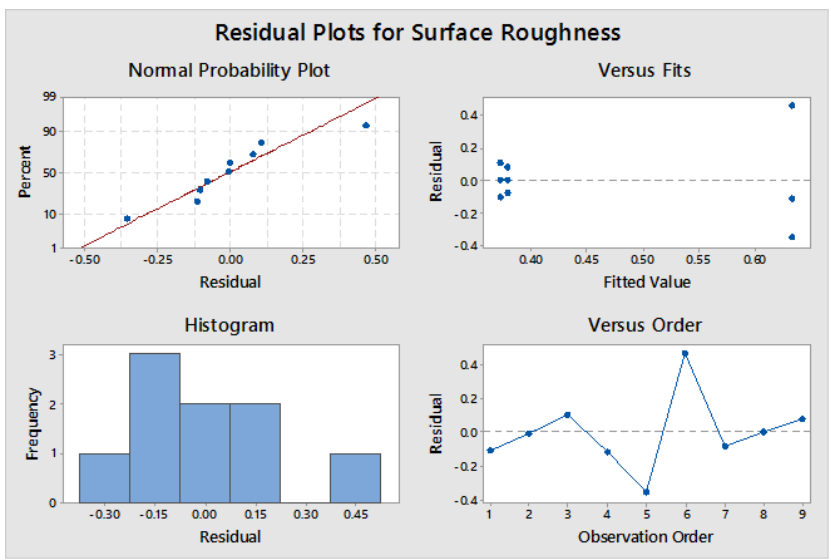

Fig. 5. Residual plots for Surface roughness

Analysis of Variance (ANOVA) results suggest the contribution of all the process parameters on the performance of micromilling operation (Table 10).

Table 10 Analysis of Variance for surface roughness

\begin{tabular}{cccccc}
\hline Source & DF & SS & MS & F & P \\
\hline Spindle Speed & 2 & 0.4455 & 0.2228 & 0.20 & 0.960 \\
Feed Rate & 2 & 0.1988 & 0.9544 & & \\
Depth of Cut & 2 & 0.2856 & 0.1428 & & \\
Residual error & 2 & 0.0701 & 0.035055 & & \\
Total & 8 & 1 & & & \\
\hline
\end{tabular}

Spindle speed has the greater influence on surface roughness $44.5 \%$, followed by depth of cut $28.56 \%$ and feed rate $20 \%$. This was also explained by figure 6 and measured value and predicted values of surface roughness was nearly same (figure 7); 


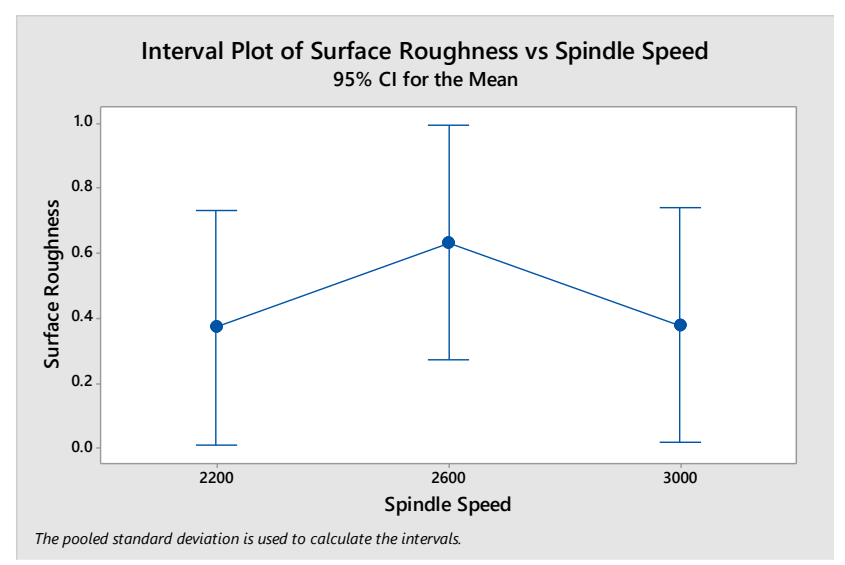

Fig. 6. Interval plot of surface roughness

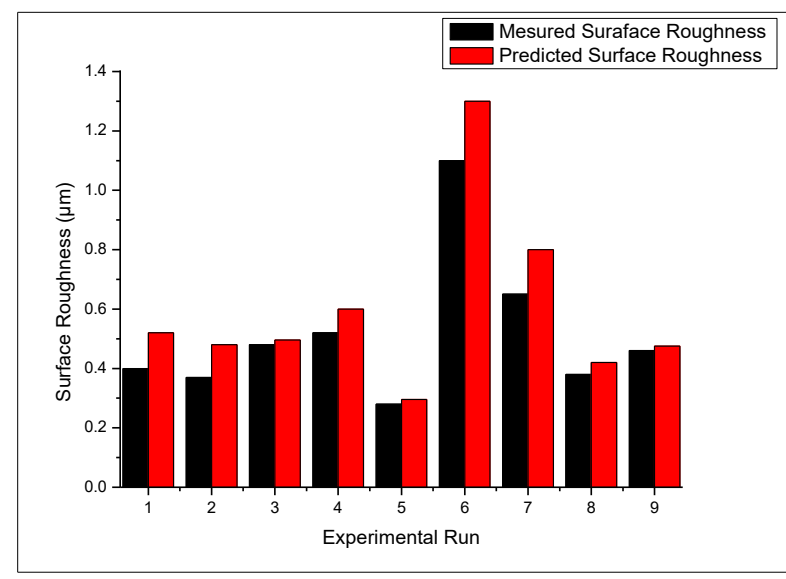

Fig. 7. Comparative study for surface roughness

Signal to noise ratio has the greater significance in optimization process and it helps to identify control factors that reduce variability in a product or process by minimizing the effects of uncontrollable factors (noise factors). Noise factors cannot be controlled during production or product use, but can be controlled during experimentation. The signal-to-noise ratio measures how the response varies relative to the nominal or target value under different noise conditions. Depending on goal of experimentation, choice to choose Signal to Noise ratio is available.

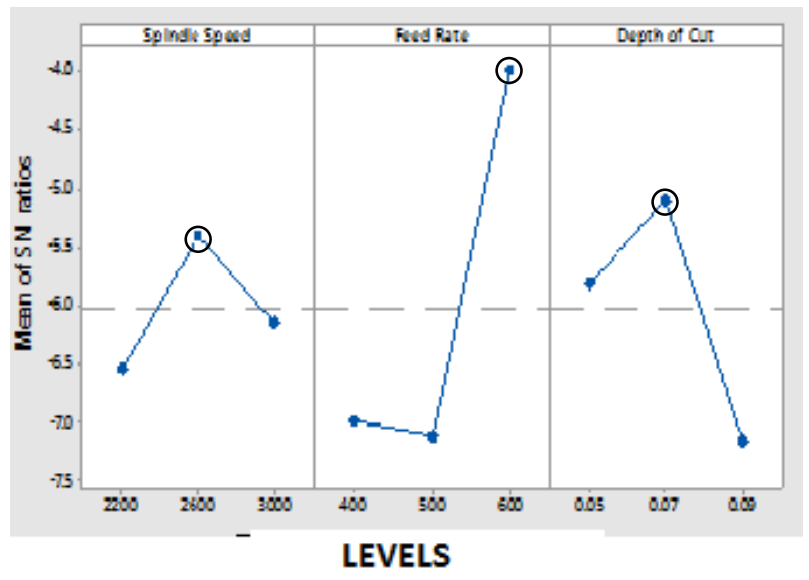

Fig. 8. S/N ratio for MRR and surface roughness

In this work, the sole aim was to reduce surface roughness and to achieve maximum metal removing rate.
So, keeping all the constraints in minds and that of signal should be always maximum than that of noise, $\mathrm{S} / \mathrm{N}$ ratio were taken as maximum the better. So it reveals the spindle speed of $2600 \mathrm{rpm}$, with feed rate of $600 \mathrm{~mm} / \mathrm{min}$ and depth of cut $0.07 \mathrm{~mm}$ gives targeted responses.

\section{Multiobjective Optimization}

The main aim of this work is to achieve maximum metal removing rate and minimum surface roughness. Hence these are opposite responses so the multiobjective optimization needs to be carried out. In multiobjective optimization, the two opposite responses MRR and surface roughness have optimized simultaneously for optimal setting of process variables (figure 9).

It was found that feed rate has greater effect on metal removing rate since increase in feed rate drastically increases the metal removing rate. The optimization graph also suggests that feed rate should be moderate with the interface of depth of cut.

While increase in spindle speed increases the surface roughness. There is slight variation in feed rate, as it does not affect too much on surface roughness. This may be due to the adhesion and abrasion wear mechanisms of aluminum material. Since aluminum has the good ductility, it might have happened in this case that serrations of plastically deformed work piece were observed.

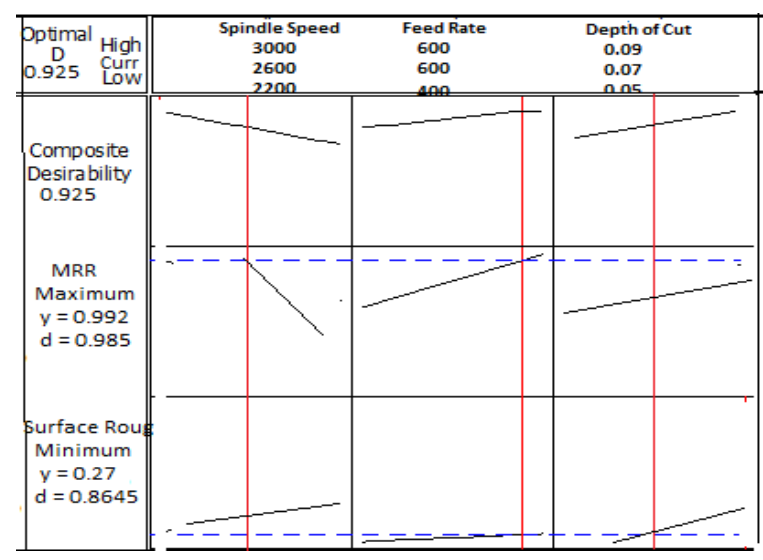

Fig. 9. Optimization graph for surface responses MRR and Surface roughness

\section{CONCLUSIONS}

- This work was carried out in three stages, experimental work, modelling and multiobjective optimization. Use of taguchi method was found out to be very significant here, as 27 experiments were reduced to 9 .

- It can be anticipated that spindle speed influences on surface roughness and that feed rate on metal removing rate too.

- Regression model was created through analysis and it was found that measured and predicted values of MRR and surface roughness were in agreement with each other.

- Signal to noise ratio reveals in the optimal settings of process variables in micromilling of Al 7075 material, as 
spindle speed of $2600 \mathrm{rpm}$, feed rate of $600 \mathrm{~mm} / \mathrm{min}$ and depth of cut $0.07 \mathrm{~mm}$ may help to achieve maximum MRR and minimum surface roughness.

- Predicted taguchi design was confirmed and it replicates in improvement of signal to noise ratio.

- Finally analysis of variance (ANOVA) suggests that feed rate contributes $65 \%$ of total process followed by spindle speed $18 \%$, depth of cut $10 \%$ and rest are other parameters.

\section{ACKNOWLEDGMENTS}

VSK and ASA want to deliberate there sincere thanks to Dr.R.S.Pawar, Principal, Shreeyash College of Engineering and Technology, Aurangabad for continuous support. We owe our deepest gratitude to Dr.P.P.Deshpande, Associate Professor, College of Engineering, Pune for his moral and encouraging enthu that laid this wok to be complete in stipulated spam of time. Again we are very thankful from the bottom of our hearts to Mr.A.A.Gnanaraj, Scientist-C from National Institute of Ocean Technology, Chennai who is the source of inspiration to us. And last but not least, our family because without their patience full support this was impossible.

\section{REFERENCES}

[1] A. Marcon, S. Melkote, K. Kalaitzidou, D. Debra, "An experimental evaluation of graphite nano platelet based lubricant in micro-milling" CIRP Annals - Manufacturing Technology, vol.59, pp141-144, (2010).

[2] V.S.Kathavate, P.R.Cheke, A.S.Adkine, "An Experimental Investigation of Micromilling" Int. Jou. of Tech. Enhancements and Emerging Engineering Research, vol.3, pp36-41, (2015).

[3] Emel Kuram , Babur Ozcelik, "Multi-objective optimization using Taguchi based grey relational analysis for micro-milling of Al 7075 material with ball nose end mill", Measurement, vol.46, pp1849-1864, (2013).

[4] Sinan Filiz, Caroline M. Conley., "An experimental investigation of micro-machinability of copper 101 using tungsten carbide micro-endmills" International Journal of Machine Tools \& Manufacture, vol.47, pp10881100, (2007).

[5] M.Y. Ali, A.S. Ong, "Fabricating micromilling tool using wire electro discharge grinding and focused ion beam sputtering", The International Journal of Advanced Manufacturing Technology, vol.31, pp501-508, (2006).

[6] X. Cheng, Z. Wang, K. Nakamoto, K. Yamazaki, "A study on the micro tooling for micro/nano milling", The International Journal of Advanced Manufacturing Technology, vol.53, pp523-533, (2011).

[7] H. Suzuki, T. Moriwaki, Y. Yamamoto, Y. Goto, "Precision cutting of a spherical ceramic molds with micro PCD milling tool”, CIRP Annals Manufacturing Technology, vol.56, pp131-134, (2007).

[8] G. Bissacco * H.N. Hansen, L. De Chiffre, "Micromilling of hardened tool steel for mould making applications" Journal of Materials Processing Technology, vol.167, pp201-207, (2005).

[9] C.R. Friedrich, "Near-cryogenic machining of polymethyl methacrylate for micromilling tool development", Materials and Manufacturing Processes, vol.15, pp667-678, (2000).

[10] K. Nakamoto, K. Katahira, H. Ohmori, K. Yamazaki, T. Aoyama, “A study on the quality of micro-machined surfaces on tungsten carbide generated by PCD micro end-milling”, CIRP Annals - Manufacturing Technology, vol.61 pp567-570, (2012).
[11] C.-J. Kim, J.R. Mayor, J. Ni, "A static model of chip formation in micro scale milling", ASME Journal of Manufacturing Science and Engineering, vol.126, pp710-718, (2004).

[12] M. Arif, M. Rahman, W.Y. San, "An experimental investigation into micro ball end-milling of silicon", Journal of Manufacturing Processes, vol.14, pp52-61, (2012).

[13] Rusnaldy, T. J. Ko, H. S. Kim, "An experimental study on micro cutting of silicon using a micromilling machine", The International Journal of Advanced Manufacturing Technology, vol.39, pp85-91, (2008).

\section{AUTHORS BIOGRAPHY}

V.S.Kathavate was born on $15^{\text {th }}$ August 1992 , in district city Beed and belongs to State of Maharashtra in India. He pursued his M.Tech. in Process Metallurgy from College Of Engineering, Pune 05 (MS), India in June 2016. He was the Gold Medalist in M.Tech. He has done his UG in Mechanical Engineering with honors in First Division with Distinction from Hitech Institute of Technology, Aurangabad 431136 (MS), India in the year 2014 .

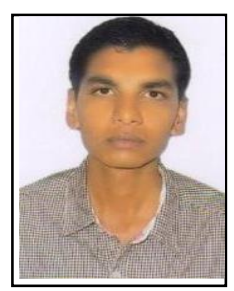

$\mathrm{He}$ is currently working as a Project Scientist-I (Mechanical) at National Institute of Ocean Technology, Pallikaranai, Chennai 600100 (TN), India which comes under the Ministry of Earth Sciences, Government of India. There he has the responsibility of Hyperbaric Testing of Subsea components and Offshore structures. Again the protection and monitoring of Galvanic corrosion in marine structures, design, anlysis and fabrication of offshore structures. His main interest lies in Heat and Mass Transfer, Micro Machining Process, Computational Fluid Dynamics, and Adiabatic multiphase flow through micro channel. Besides that Corrosion and its prevention is also his area of research. During his UG he has done the major research work on micromachining process. Optimization of process parameters is the main task which he dealt with now a day. He has the 5 years experience of Taguchi method. He has also attended the various International Conferences on Mechanical Engineering, Materials Sciences and furnished the various research papers in them. He also has his publications in International Journals which are indexed by Scopus and Google Scholars

V.S.Kathavate is the life time member of Indian Institute of Metal (IIM), Pune Chapter and Alumni Association, College of Engineering, Pune.

Prof. A.S.Adkine was born on $09^{\text {th }}$ September 1981 , in district city Parbhani and belongs to State of Maharashtra in India. He pursued his M.E. in Manufacturing Engineering from Shree Tuljabhavani Trust' College of Engineering, Tuljapur (MS), India in 2013. He has done his UG in Mechanical Engineering in First Division with Distinction from Shree Tuljabhavani Trust' College of Engineering, Tuljapur (MS), India in 2007.

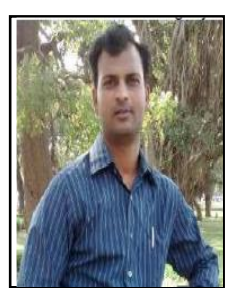

$\mathrm{He}$ is currently working as a Assistant Professor in Shreeyash College of Engineering and Technology, Aurangabad (MS), India. His main enthu stands in the subjects like Theory of Machines, Mechanical Drawing and Management related subjects. During his career he is very well known and versatile personality among his subordinates. Currently his ongoing research is on static and dynamic behaviour of engine mounting bracket. Prof. Adkine had attended and conducted the various workshops and sessions on various subjects like Vibration analysis, ANSYS software tools, Rapid prototyping, and various Manufacturing process. 